\title{
A Comparison of Plasma Copeptin and AVP Responses During Saline Infusion Studies
}

\section{Christopher Boot ${ }^{1}$, Louise Hughes ${ }^{1}$, Steve Turner ${ }^{1}$, Steve Ball 2,3 and Dermot Neely ${ }^{1}$}

1. Blood Sciences, Royal Victoria Infirmary, Newcastle upon Tyne Hospitals NHS Trust

2. Department of Endocrinology, Newcastle upon Tyne Hospitals NHS Foundation Trust. 3. School of Medicine, Newcastle University

\section{INTRODUCTION}

Copeptin is the C-terminal fragment of proAVP and secreted in equimolar amounts with AVP. While AVP is unstable in vitro and has proved difficult to measure in clinical practice, copeptin is relatively stable and can be measured using an automated immunoassay. Therefore copeptin measurement offers potential as a more practical alternative to the direct measurement of AVP in the investigation of polyuria/polydipsia.

\section{METHODS}

AVP, Copeptin and plasma osmolality were measured in parallel plasma samples from 15 patients undergoing a hypertonic saline stress test, AVP and Copeptin values were correlated with plasma osmolality using an in-house normogram allowing comparison of AVP response to a reference population. AVP and copeptin responses to hypertonic stress were compared.

\section{RESULTS}

In 12 cases the AVP response was considered normal. In 3 cases the AVP response was considered sub-normal, with AVP failing to demonstrate sufficient response to an osmotic stimulus, consistent with cranial diabetes insipidus. In all 15 cases the response of copeptin was equivalent to that of AVP. In all 12 cases with a normal AVP response, the peak copeptin was at least 12.7 pmol/L (range 12.7 to 73.4 ) and copeptin concentration was at least $4.6 \mathrm{pmol} / \mathrm{L}$ in samples with osmolality $\geq 300 \mathrm{mOsm} / \mathrm{L}$. In the 3 cases with a sub-normal AVP response consistent with diabetes insipidus, 2 were associated with very poor copeptin response (maximum copeptin $\leq 2.6 \mathrm{pmol} / \mathrm{L}$ ). In the remaining case both AVP and copeptin responses were below the expected normal range.
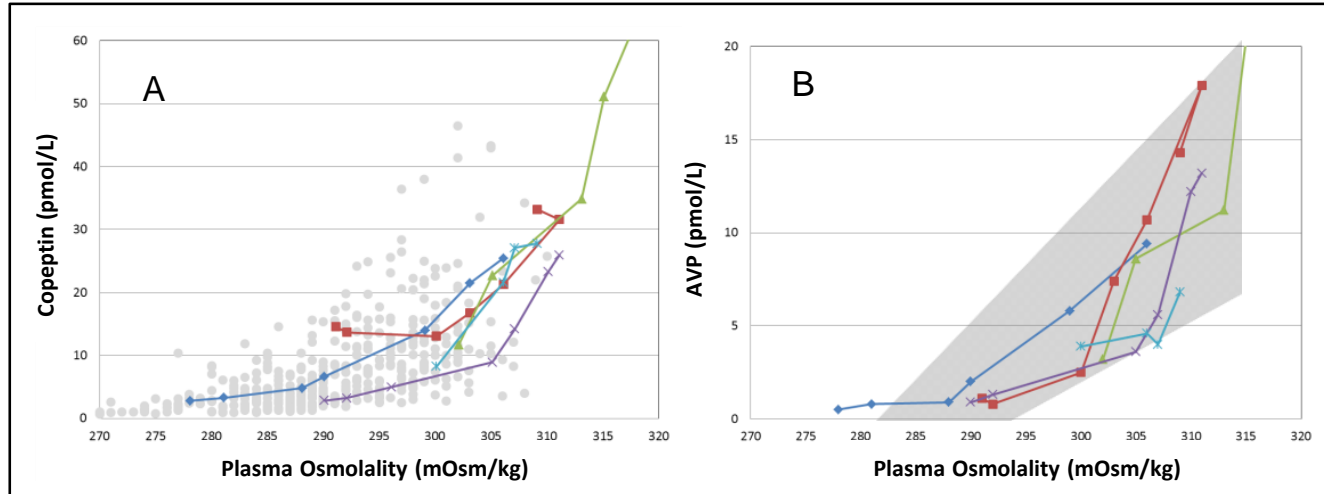

Figure 1. Copeptin (A) and AVP (B) responses during saline infusion for 5 of the patients with normal AVP response.

Copeptin results plotted against published data from 44 healthy individuals ${ }^{1,2}$

AVP results plotted against inhouse reference data.
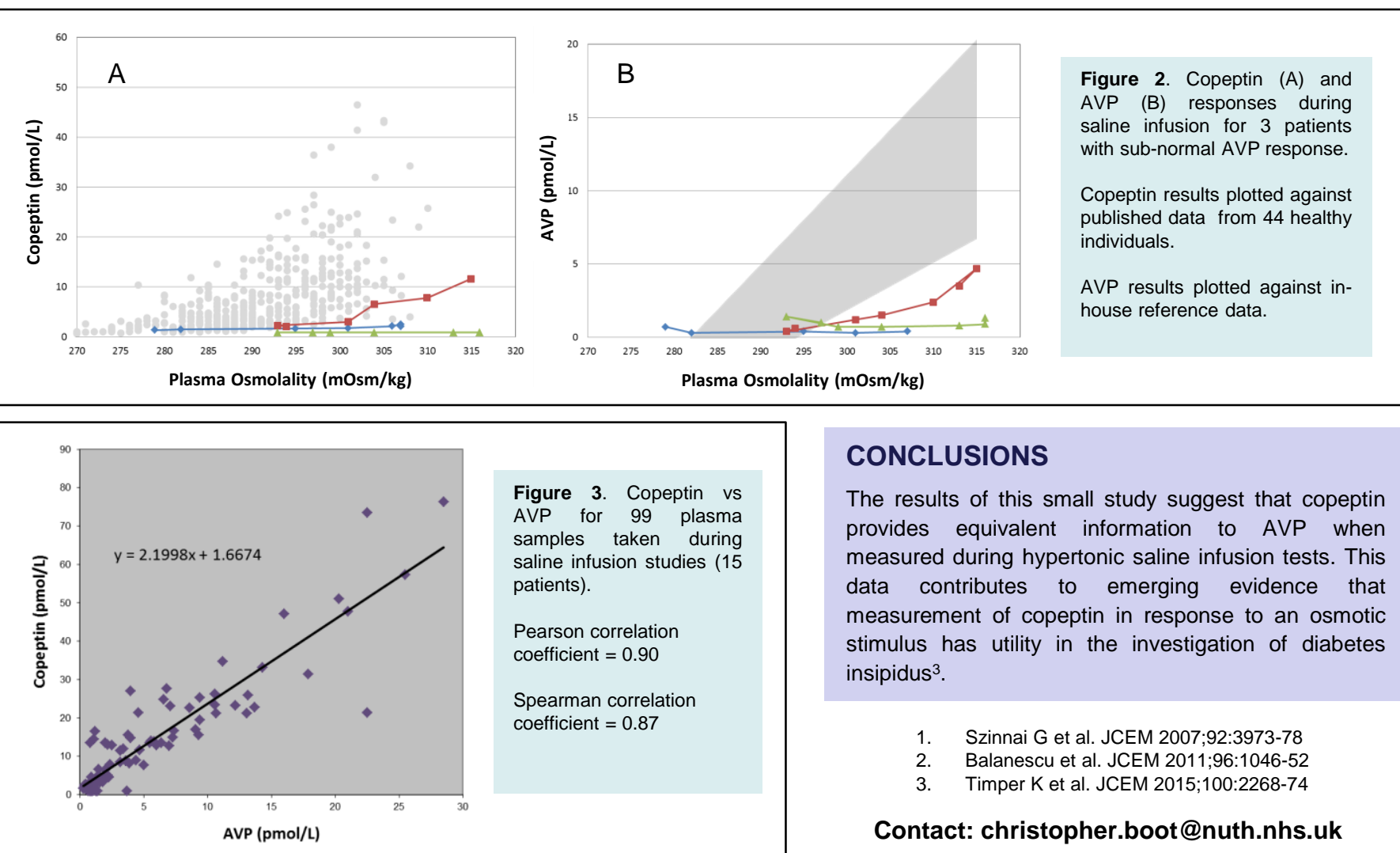

\section{CONCLUSIONS}

The results of this small study suggest that copeptin provides equivalent information to AVP when measured during hypertonic saline infusion tests. This data contributes to emerging evidence that measurement of copeptin in response to an osmotic stimulus has utility in the investigation of diabetes insipidus ${ }^{3}$.

1. Szinnai G et al. JCEM 2007:92:3973-78

2. Balanescu et al. JCEM 2011;96:1046-52

3. Timper K et al. JCEM 2015;100:2268-74 